\title{
INTERACTION OF SILVER NANOPARTICLES WITH VANCOMYCIN: AN UV-VIS STUDY
}

\author{
REKA BALINT ${ }^{a}$, GERTRUD ALEXANDRA PALTINEAN ${ }^{a}$, \\ AURORA MOCANU ${ }^{a^{*}}$, OSSI HOROVITZa, MARIA TOMOAIA-COTISEL ${ }^{a}$
}

\begin{abstract}
Silver nanoparticles (AgNPs) were synthesized by chemical reduction method, using different reducing systems. The interaction of AgNPs and vancomycin hydrochloride (V) was investigated by UV-Vis spectroscopy, and their tendency to form AgNP@V associations or complexes was identified in colloidal solutions. Moreover their affinity to self-assembly and aggregate is also examined. This behavior is important and decisively influences the antimicrobial effect of AgNP@V complexes.
\end{abstract}

Keywords: silver nanoparticles, vancomycin, UV-VIS spectroscopy

\section{INTRODUCTION}

The current need for novel syntheses and functionalization methods of silver nanoparticles (AgNPs) for gaining an enhanced antimicrobial activity represents a great challenge in the development of new antimicrobials.

Many investigations are made nowadays regarding AgNPs, in particular their effect in various combinations with drugs, like antibiotics, leading to new strategies for their therapeutic use [1, 2].

Firstly, AgNPs can be used as antimicrobial agents [2-6]. Further, they can also improve the activity of antibiotics, reducing their secondary effects [7], and even make them active against bacterial strains resistant to those antibiotics. Moreover, the AgNPs and antibiotics were jointly found effective against pathogenic bacteria, which have developed resistance against certain antibiotics, because of the abusive uses of antibiotics [8-12].

\footnotetext{
a Babeş-Bolyai University, Faculty of Chemistry and Chemical Engineering, Research Center of Physical Chemistry, 11 Arany Janos str., RO-400028, Cluj-Napoca, Romania

*Corresponding author: mocanu.aurora@gmail.com
} 
In this regard, the method by which AgNPs were obtained is of major importance. If they are synthesized by chemical reduction method, the reducing agent can also stabilize the colloidal system [13,14], or other substances are introduced, as capping agents [15]. They may determine the size and shape of the particles. Clearly, the interactions between the drug and silver can be mediated by capping agents.

These interactions can stabilize, but also can destabilize the colloidal system, causing the aggregation of the nanoparticles and finally their precipitation. These interactions can also influence the biological effects of the system, leading to a synergistic, additive effect or antagonistic effect of AgNPs and drug [16]. Even the orientation of drug molecules on the AgNPs can play an important role [11].

The methods to synthesize AgNPs are numerous and varied $[2,17]$, going from physical approaches, to chemical or electrochemical reduction processes, and to biogenic (green) syntheses [18, 19], often by plant extracts [20-23], fungi and bacteria [16, 24, 25]. $\mathrm{Ag}^{+}$ions can be easily reduced even by weak reducing agents, both inorganic and organic $[6,26]$. In order to better control the particles size and shape, mixtures of different reducing agents were also used (co-reduction) [17, 27-29]. Of course, the cytotoxicity of AgNPs and also their impact on medium must be taken into account [30].

Vancomycin, $\mathrm{C}_{66} \mathrm{H}_{75} \mathrm{Cl}_{2} \mathrm{~N}_{9} \mathrm{O}_{24}$, is a large glycopeptide, noted $\mathrm{V}$, active generally against Gram-positive bacteria. It is mostly used in the form of hydrochloride. Vancomycin is largely used as an alternative to antibiotics for which drug resistance was developed. Unfortunately, even strains resistant to vancomycin already emerged [31]. Therefore, associating vancomycin with silver nanoparticles could be a solution [32].

Consequently, the focus of this work is on syntheses and functionalization of AgNPs with an antibiotic, like vancomycin, to obtain homogeneous colloidal solutions, having narrow sized particles, of high stability.

\section{RESULTS AND DISCUSSION}

Silver reduction with citrate ions is frequently used to obtain AgNPs, and also to stabilize them, but that mechanism in not yet fully understood [33]. The spectra of AgNPs obtained by reduction with trisodium citrate ( $C$ ) and their mixtures with vancomycin hydrochloride $(V)$ solution in different ratios are given in Figure 1. The peak at about $280 \mathrm{~nm}$ is due to vancomycin hydrochloride. The characteristic surface plasmon resonance (SPR) band of AgNPs has a maximum at $406 \mathrm{~nm}$, denoting the presence of rather small nanoparticles. 
There is a single sharp peak indicating the presence of mostly spherical AgNPs [12]. The full width at half maximum (FWHM) is $76.8 \mathrm{~nm}$, showing a rather narrow distribution of particles size (namely, of low polydispersivity).

By adding increasing volumes of $\mathrm{V}$ solution, the maximum decreases, due to the dilution of the AgNPs solution and is shifted toward higher wavelengths (red shift). This significant shift is the result of the interactions between $\mathrm{Ag}$ and the drug. The width of the peak (FWHM) also increases with increasing amounts of $V$, up to $78.5 \mathrm{~nm}$, due to the formation of the AgNP@V complex [11]. After 2 days the spectrum is only slightly modified, so the AgNP@V associations are stable, without a tendency to aggregate. The interaction between vancomycin and citrate capped AgNPs can be assigned to hydrogen bond between the oxygen atoms of citrate anion and the $\mathrm{H}$ atom in the amino groups of vancomycin, in total agreement with other similar data [12].

The reduction of $\mathrm{Ag}^{+}$with $\beta$-cyclodextrin $(\beta-\mathrm{CD})$ is a green synthesis [34] The UV-Vis spectrum (Fig. 2) is quite similar to that of AgNP-citrate (Fig. 1). From TEM images, an average size of the particles of $13.1 \pm 2.1 \mathrm{~nm}$ was found [34]. The particle distribution is narrower (FWHM $=69.6 \mathrm{~nm})$ than for the reduction with citrate. The addition of $V$ causes also a red shift of the absorption maximum. But after several days a deformation of the SPR peak occurs, with the apparition of a shoulder at higher wavelengths and a corresponding increase of the FHWM, to over $100 \mathrm{~nm}$. This indicates the beginning of self-assembly of the AgNPs mediated by vancomycin.

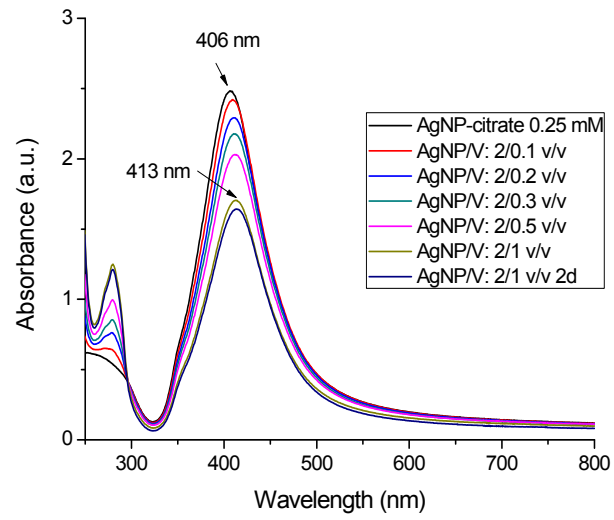

Figure 1. UV-VIS spectra of AgNPscitrate and $\mathrm{V}$ solutions in different ratios and in time

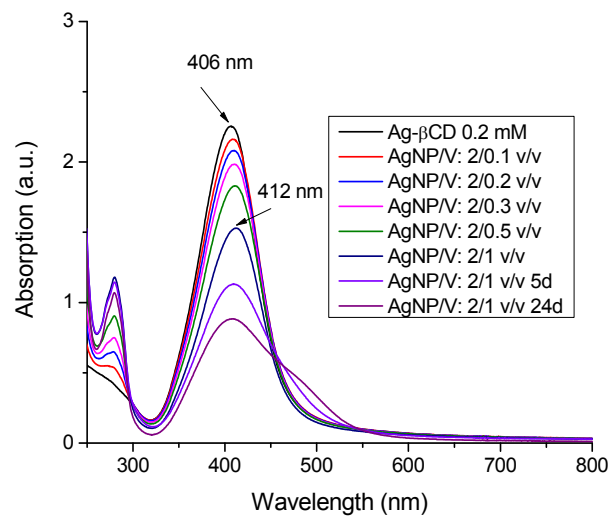

Figure 2. UV-VIS spectra of AgNPs$\beta$-cyclodextrin $(\beta-C D)$ and $V$ solutions in different ratios and in time 
Another green synthesis of AgNPs uses glucose as reducing agent and starch as capping agent $[35,36]$. The maximum of the SPR band of the AgNPs is at $406 \mathrm{~nm}$ (Fig. 3), and the FWHM is $56.2 \mathrm{~nm}$. The peak is not shifted by adding $\mathrm{V}$, but after 2 days a shoulder appears at about $470 \mathrm{~nm}$, and a new peak appears after 3 days, at $508 \mathrm{~nm}$, while the main peak is much diminished. The new peak corresponds to aggregates of AgNPs resulted by their self-assembly. In presence of starch, the vancomycin mediated selfassembly is more accentuated than for other capping agents.

The synthesis of AgNPs, using also glucose as reducing agent and tetraethyl orthosilicate (TEOS) [37] as capping agent (Fig. 4), produced larger AgNPs. The maximum absorption in the SPR band occurs at about $410 \mathrm{~nm}$, and the band is asymmetrical, outstretched toward higher wavelengths, and FWHM is about $80 \mathrm{~nm}$. This finding means that there is a wider distribution of particles sizes, and larger particles being also present. This asymmetry increases when $V$ is added, and in time. After 4 days the maximum of the SPR band is significantly reduced, and the $V$ band is at $280 \mathrm{~nm}$. The cause is the precipitation of larger aggregated AgNPs.

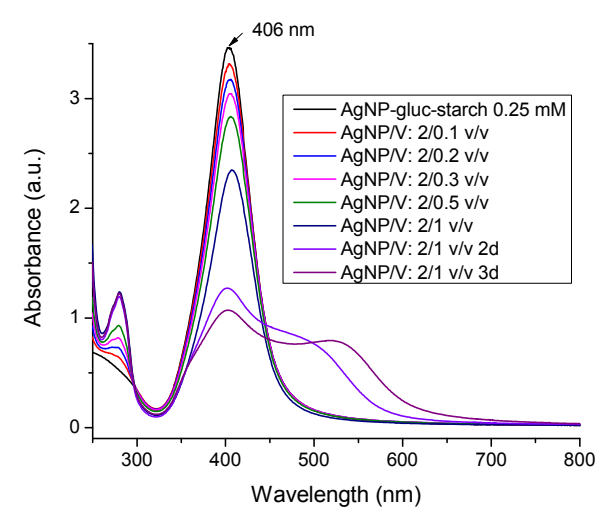

Figure 3. UV-VIS spectra of AgNPsglucose-starch (gluc-starch) and $\mathrm{V}$ solutions in different ratios and in time

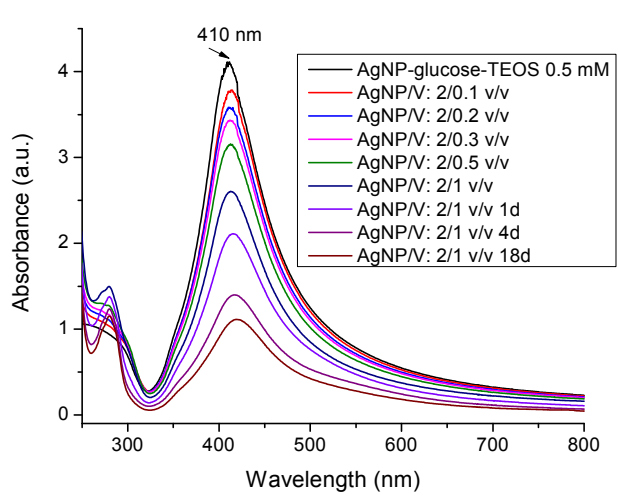

Figure 4. UV-VIS spectra of AgNPsglucose -TEOS and $V$ solutions in different ratios and in time

Using a mixture of trisodium citrate $(C)$ and tannic acid (T) [17] (Fig. 5) in the molar ratio of 1:7:2 for Ag:C:T, relatively large AgNPs are obtained. In the presence of $\mathrm{V}$, the absorption maximum of the SPR band shifts toward red. The AgNPs are stable, no tendency to aggregation is observed in time. The absorption band of $V$ at $280 \mathrm{~nm}$ is not visible, since it is hidden by the strong absorption band of tannic acid. 


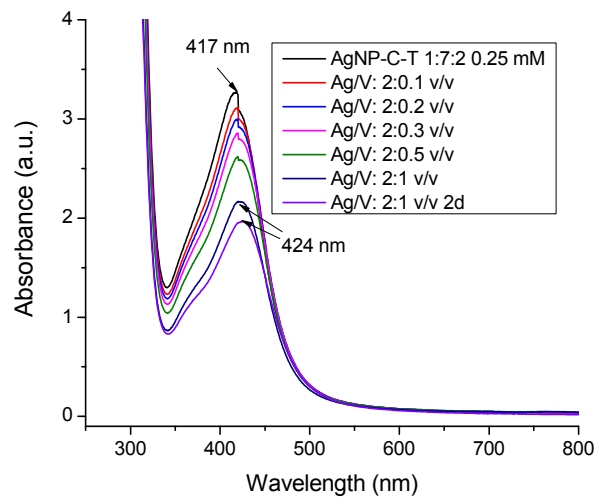

Figure 5. UV-VIS spectra of AgNPscitrate $(\mathrm{C})$ and tannic acid $(\mathrm{T})$ in the molar ratio 1:7:2 and $V$ solutions in different ratios and in time

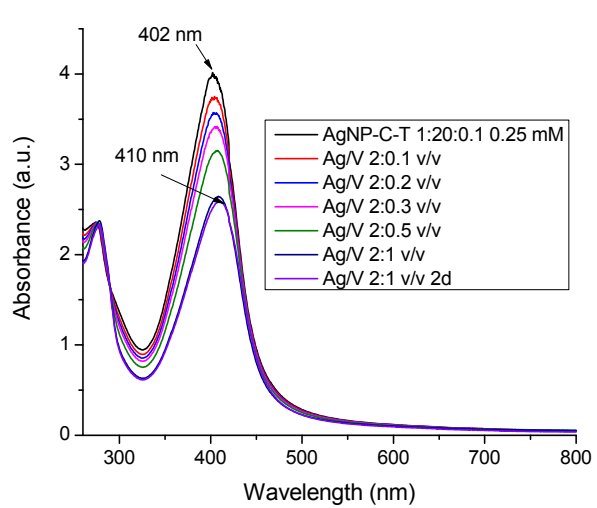

Figure 6. UV-VIS spectra of AgNPscitrate $(\mathrm{C})$ and tannic acid $(\mathrm{T})$ in the molar ratio $1: 20: 0.1$ and $V$ solutions in different ratios and in time

With a much lower tannic acid concentration (Ag:C:T molar ratio of 1:20:0.1) the AgNPs are much smaller (absorption maximum at $402 \mathrm{~nm}$ ) and the SPR band is quite narrow (low polydispersivity). The band is red shifted for increasing $V$ addition, which is a sign of vancomycin association to AgNPs (Fig. 6). No significant modifications are observed in time.

The vancomycin-AgNPs complexes are stable, no aggregation and precipitation occur. The $\mathrm{V}$ band of $280 \mathrm{~nm}$ is here superposed on a stronger tannic acid band at the same position, so its variation with the $V$ content of the solution is no longer visible,

The UV-Vis spectra of $\mathrm{V}$ mixtures with silver nitrate solution are compared with the spectra of $\mathrm{V}$ and $\mathrm{AgNO}_{3}$ in Fig. 7. $\mathrm{AgNO}_{3}$ presents no absorption in the visible and UV wavelength range investigated, and no SPR band appears.

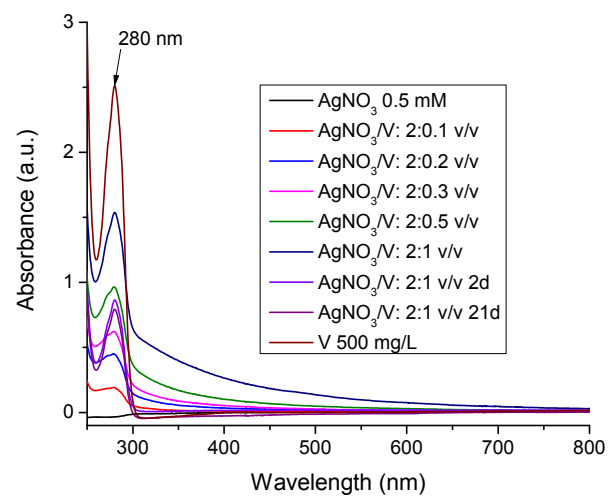

Figure 7. UV-VIS spectra of $0.5 \mathrm{mM} \mathrm{AgNO}_{3}$ and $500 \mathrm{mg} / \mathrm{L}$ vancomycin hydrochloride (V) solutions and their mixtures, and in time 
Vancomycin can also reduce $\mathrm{Ag}^{+}$to AgNPs, but only in basic medium and at higher temperature [unpublished research]. The $V$ band at $280 \mathrm{~nm}$ increases with $V$ concentration in that mixture, but in several days a diminution of its intensity is observed. Only after $21 \mathrm{~d}$, traces of a gray deposit are seen (indicating that silver ions are reduced by $\mathrm{V}$ ).

\section{CONCLUSIONS}

UV-Vis measurements enabled us to highlight the various behavior of AgNPs colloidal solutions, obtained using various reduction systems, due to the formation of differently capped AgNPs. Further, the interaction of the capped AgNPs with the antibiotic drug, like vancomycin, is identified.

For some preparations (e.g. AgNPs-citrate or AgNPs-citrate-tannic acid) stable AgNPs-vancomycin associations (complexes) were obtained. For other colloidal solutions (e.g. AgNPs- $\beta C D$ ) less or more advanced vancomycin mediated self-assemblies of AgNPs appeared, and still maintained in colloidal solution. Finally, in other systems (e.g. AgNPs-glucose-starch or AgNPs-glucoseTEOS), the AgNPs slightly precipitated under the influence of vancomycin.

Clearly, the knowledge on the characteristic behavior of AgNPsvancomycin systems can help in the selection of appropriate systems in order to maximize their antimicrobial effect.

\section{EXPERIMENTAL SECTION}

\section{Synthesis of silver nanoparticles}

For all syntheses $\mathrm{AgNO}_{3}$ solution was used (high purity silver nitrate from Merck). For the reduction with trisodium citrate [17, 38], $25 \mathrm{~mL} 1 \mathrm{mM}$ $\mathrm{AgNO}_{3}$ were boiled with $5 \mathrm{~mL} 1 \%$ solution of trisodium citrate, C, $\left(\mathrm{Na}_{3} \mathrm{C}_{6} \mathrm{H}_{5} \mathrm{O}_{7} \cdot 2 \mathrm{H}_{2} \mathrm{O}\right.$, high purity, from Sigma Aldrich) and $70 \mathrm{~mL}$ water for 30 min, under continuous stirring, The mole ratio $\mathrm{C}: \mathrm{Ag}$ was about 7:1. The pale yellow solution obtained $(0.25 \mathrm{mM} \mathrm{Ag})$ was cooled on an ice-water mixture at room temperature.

$\beta$-Cyclodextrin (Sigma-Aldrich) was used as a $10^{-2} \mathrm{M}$ aqueous solution to reduce a $10^{-2} \mathrm{M} \mathrm{AgNO}_{3}$ solution in the 9:1 volume ratio, at $\mathrm{pH} 9$ (adjusted with $\mathrm{K}_{2} \mathrm{CO}_{3}$ ). The colloidal AgNPs solution obtained was diluted to $0.2 \mathrm{mM} \mathrm{Ag}$ [34].

AgNPs-glucose-starch solution [35] was prepared from $20 \mathrm{~mL} \mathrm{10-3}$ $\mathrm{M} \mathrm{AgNO}_{3}$ solution by reduction with $1.36 \mathrm{~mL} 4 \%$ glucose solution (obtained from glucose B. Braun $100 \mathrm{mg} / \mathrm{mL}$, Melsungen AG, Germany) and $50 \mathrm{~mL}$ 
$0.34 \%$ starch solution (soluble starch, p.a. from Chempur, Poland) with ultrapure water to a total volume of $80 \mathrm{~mL}$. The solution was heated under continuous stirring until boiling, when the $\mathrm{pH}$ was set at 7 with $10 \% \mathrm{NaOH}$ solution and boiled for other $15 \mathrm{~min}$. The obtained $0.25 \mathrm{mM} \mathrm{Ag}$ solution was cooled to room temperature. The glucose:Ag mole ratio was 1.2:1.

The AgNPs-glucose-TEOS solution [37] was obtained from $100 \mathrm{~mL}$ $10^{-3} \mathrm{M} \mathrm{AgNO}_{3}$ solution and $100 \mathrm{~mL}$ solution prepared from $5.2 \mathrm{~mL} 4 \%$ glucose solution, $1 \mathrm{~mL} 0.4 \%$ TEOS solution in ethanol (from Merck) and ultrapure water. The two solutions were separately heated to $50{ }^{\circ} \mathrm{C}$ under stirring, and then, they were mixed and $10 \% \mathrm{NaOH}$ solution was added to reach $\mathrm{pH}$ 10. The AgNPs solution with $0.5 \mathrm{mM}$ Ag had a glucose:Ag mole ratio of 2.3:1.

The AgNPs-citrat-tannic acid colloidal solutions with the mole ratios 1:7:2 and 1:20:0.1 for Ag:C:T mole ratios, and a final Ag concentration of $0.25 \mathrm{mM}[17,39]$ were prepared by heating up the $10^{-2} \mathrm{M} \mathrm{AgNO}_{3}$ solution until boiling, and then adding the solution containing the calculated amount of trisodium citrate and tannic acid (purchased from Merck). The solutions were kept boiling, under continuous stirring, for $15 \mathrm{~min}$.

\section{Interaction of AgNPs with vancomycin}

Vancomycin hydrochloride $\left(\mathrm{V}, \mathrm{C}_{66} \mathrm{H}_{75} \mathrm{Cl}_{2} \mathrm{~N}_{9} \mathrm{O}_{24} \cdot \mathrm{HCl}\right)$ was purchased from Xellia Pharmaceuticals ApS Denmark, and a $500 \mathrm{mg} / \mathrm{L}$ aqueous solution $(0.336 \mathrm{mM})$ was prepared and used in the subsequent experiments. In each experiment, $2 \mathrm{~mL}$ of AgNPs colloidal solution was used and different volumes of vancomycin solution (up to $1 \mathrm{~mL}$ ) were successively added.

The UV-VIS absorption spectra were measured with a Jasco UV/Vis V650 spectrophotometer, from 800 to $250 \mathrm{~nm}$ wavelength for the AgNPs colloidal solution and for the mixtures containing $2 \mathrm{~mL}$ AgNP solution and $0.1 ; 0.2 ; 0.3 ; 0.5$ and $1 \mathrm{~mL} \vee$ solution. The measurements for the last mixture were repeated after several days. For comparison, the interaction between a $0.5 \mathrm{mM} \mathrm{AgNO}_{3}$ solution with vancomycin solution was investigated in the same conditions.

\section{ACKNOWLEDGMENTS}

Authors acknowledge the financial support from Executive Unit for Financing Higher Education, Research, Development and Innovation (UEFISCDI) through the research project number 83 . 
REKA BALINT, GERTRUD ALEXANDRA PALTINEAN, AURORA MOCANU, OSSI HOROVITZ, MARIA TOMOAIA-COTISEL

\section{REFERENCES}

1. B. Calderón-Jiménez; M. E. Johnson; A. R. M. Bustos; K. E. Murphy; M. R. Winchester; J. R. V Baudrit; Front. Chem., 2017, 5, Article 6. doi: 10.3389/ fchem.2017.00006

2. S. U. Khan; T. A Saleh; A. Wahab; M. H. U. Khan; D. Khan; W. U. Khan; A. Rahim; S. Kamal; F. U. Khan; S. Fahad; Int. J. Nanomedicine, 2018, 13, 733762

3. M. Rai; A. Yadav; A. Gade; Biotechnol. Adv., 2009, 27, 76-83

4. M. K. Rai; S. D. Deshmukh; A. P. Ingle; A. K. Gade; J. Appl. Microbiol., 2012, 112, 841-852

5. H. H. Lara; N. V. Ayala-Núnez; L. del C. I. Turrent; C. R. Padilla; World J. Microbiol. Biotechnol., 2010, 26, 615-621

6. L. Ge; Q. Li; M. Wang; J. Ouyang; X. Li; M. M. Q. Xing; Int. J. Nanomedicine, 2014, 9, 2399-2407

7. A. Coates; Y. Hu; R. Bax; C. Page; Nat. Rev. Drug Discov., 2002, 1, 895-910

8. W. Q. Shan; J. Jian; F. J. Hong; S. J. Cong; Sci. China B Chem., 2007, 50, 418-424

9. Y. E. Hur; Y. Park; J. Nanosci. Nanotechnol., 2016, 16, 6393-6399

10. N. Xu; H. Cheng; J. Xu; F. Li; B. Gao; Z. Li; C. Gao; K. Huo; J. Fu; W. Xiong; Int. J. Nanomedicine, 2017, 12, 731-743

11. A. Kaur; D. Goyal; R. Kumar; Appl. Surf. Sci., 2018, 449, 23-30

12. A. Kaur; S. Preet; V. Kumar; R. Kumar; R. Kumar; Colloids Surf. B: Biointerfaces, 2019, 176, 62-69

13. A. Mocanu; R.D. Pasca; Gh. Tomoaia; C. Garbo; P.T. Frangopol; O. Horovitz; M. Tomoaia-Cotisel; Int. J. Nanomedicine, 2013, 8, 3867-3874

14. G. Furtos; M. Tomoaia-Cotisel; C. Garbo; M. Senila; N. Jumate; I. Vida-Simiti; C. Prejmerean; Particul. Sci. Technol., 2013, 31(4), 392-398

15. C. T. Matea; T. Mocan; F. Tabaran; T. Pop; O. Mosteanu; L. Mocan; C. Zdrehus; Studia UBB Chemia, 2018, 63, 95-102

16. M. Wypij; J. Czarnecka;-M. Świecimska; H. Dahm;-M. Rai; P. Golinska; World J. Microbiol. Biotechnol. 2018, 34:23. doi.org/10.1007/s11274-017-2406-3

17. S. Rapuntean; R. Balint; G. A. Paltinean; Gh. Tomoaia; A. Mocanu; C. P. Racz; O. Horovitz; M. Tomoaia-Cotisel; Studia UBB Chemia, 2018, 63, 73-85

18. N. Arjunan; H.L.J. Kumari; C. M. Singaravelu; R. Kandasamy; J. Kandasamy; Int. J. Biol. Macromol., 2016, 92, 77-87

19. P. K. Ponnaian; R. Oommen; S. K. C. Kannaiyan; S. Jayachandran; M. Natarajan; A. Santhanam; J. Environ. Nanotechnol., 2015, 4, 23-26

20. S. Ahmed; M. Ahmad; B. L. Swami; S. Ikram; J. Adv. Res. 2016, 7, 17-28

21. T. A. Abalkhil; S. A. Alharbi; S. H. Salmen; M. Wainwright; Biotechnol. Biotechnol. Equip., 2017, 31, 411-417

22. K. S. Siddiqi; A. Husen; R. A. K. Rao; J. Nanobiotechnol., 2018, 16:14, https://doi.org/10.1186/s12951-018-0334-5 
23. P. Singh; S. Pandit; J. Garnæs; S. Tunjic; V. R. S. S. Mokkapati; A. Sultan; A. Thygesen; A. Mackevica; R. V. Mateiu; A. E. Daugaard; A. Baun; I. Mijakovic; Int. J. Nanomedicine, 2018,13, 3571-3591

24. S. Z. H. Naqvi; U. Kiran; M. I. Ali; A. Jamal; A. Hameed; S. Ahmed; N. Ali; Int. J. Nanomedicine, 2013, 8, 3187-3195

25. B. Momin; S. Rahman; N. Jha; U. S. Annapure; Bioprocess. Biosyst. Eng., 2019, 42, 541-553

26. M. Tomoaia-Cotisel; Multifunctional nanostructures formed of gold or silver nanoparticles and different biomolecules with medical applications, e-Book, Cluj University Press, Cluj-Napoca, 2016, pp. 1-322 http://www.editura.ubbcluj.ro/bd/ebooks/pdf/1976.pdf

27. S. Agnihotri; S. Mukherji; S. Mukherji; RSC Advances, 2014, 4, 3974-3983

28. K. Ranoszek-Soliwoda; E. Tomaszewska; E. Socha; P. Krzyczmonik; A. Ignaczak; P. Orlowski; M. Krzyzowska; G. Celichowski; J. Grobelny; J. Nanopart. Res., 2017, 19, article 273, https://doi.org/10.1007/s11051-017-3973-9

29. L. Salvioni; E. Galbiati; V. Collico; G. Alessio; S. Avvakumova; F. Corsi; P. Tortora; D. Prosperi; M. Colombo; Int. J. Nanomedicine, 2017, 12, 2517-2530

30. M. Akter; M. T. Sikder; M. M. Rahman; A. K. M. A. Ullah; K. F. B. Hossain; S. Banik; T. Hosokawa; T. Saito; M. Kurasaki; J. Adv. Res., 2018, 9, 1-16

31. B. P. Howden; J. K. Davies; P. D. R. Johnson; T. P. Stinear; M. L. Grayson; Clin. Microbiol. Rev., 2010, 23, 99-139

32. M. Esmaeillou; G. Zarrini; M. A. Rezaee; J. S. Mojarrad; A. Bahadori; Adv. Pharm. Bull., 2017, 7, 479-483

33. Y. L. Mikhlin; S. A. Vorobyev; S. V. Saikova; E. A. Vishnyakova; A. S. Romanchenko; S. M. Zharkov; Y. V. Larichev; Appl. Surf. Sci., 2018, 427, 687-694

34. A. Mocanu; O. Horovitz; C. P. Racz; M. Tomoaia-Cotisel; Rev. Roum. Chim., 2015, 60,721-726

35. L. Ortega-Arroyo; E. S. Martin-Martinez; M. A. Aguilar-Mendesz; A. Cruz-Orea; I. Hernandez-Pérez; C. Glorieux; Starch, 2013, 65, 814-821

36. S. V. Kumar; A. P. Bafana; P. Pawar; A. Rahman; S. A. Dahoumane; C. S. Jeffryes; Sci. Rep., 2018, 8:5106, DOI:10.1038/s41598-018-23480-6

37. A. Mocanu; G. Furtos; S. Rapuntean; O. Horovitz; C. Flore; C. Garbo; A. Danisteanu; Gh. Rapuntean; C. Prejmerean; M. Tomoaia-Cotisel; Appl. Surf. Sci., 2014, 298, 225-235

38. O. Horovitz; M. Tomoaia-Cotisel; C. Racz; Gh. Tomoaia; L. D. Bobos; A. Mocanu; Studia UBB Chemia, 2009, 54, 89-96

39. N. G. Bastús; F. Merkoçi; J. Piella; V. Puntes; Chem. Mater., 2014, 26, 2836-2846. 